\title{
Editorial Introduction to ACT 16.2
}

\author{
Vincent C. Bates, Editor
}

This editorial introduction to ACT 16 (2) includes an argument for immanent critique within the MayDay Group or, in other words, it underscores the importance of remaining open to criticism within and/or directed toward the group. This is followed by overviews for each of the five research articles in this issue, a brief discussion of what to expect in ACT through the rest of 2017 through 2018, and expressions of gratitude to all who volunteer their time and expertise to maintaining this important open-access, double-blind peer reviewed journal.

Keywords: MayDay Group, critical theory, immanent critique

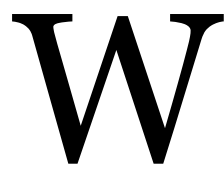

hen the MayDay Group was first organized in 1993 in Buffalo, New York, I was more than 2,ooo miles away in Eureka, Utah, just fresh out of university and starting my first music teaching job. I didn't learn of the group until nearly a decade later as a doctoral student at the University of Arizona studying with the late Steve Paul, one of the early MDG participants. Since then I have enjoyed participating with the group, particularly in a number of capacities with ACT. While I haven't been one of the primary movers in shaping the MDG, I do recognize and honor its roots as an international "think-tank" for critical inquiry in the field of music education.

Critical theory, with its emancipatory aims and immanent critique, continues to figure prominently in ACT and the MDG as we strive together, not only to explore and explain the rich terrain of music education, but also to change it for the better. Immanent critique calls upon us to delve deeply within social structures and apply critical or dialectical processes to challenge potentially inconsistent and oppressive practices. Because we exist within many of these same social structures, the scope of critique must necessarily be comprehensive and include our own work. In fact, without fully contextualizing or situating our own practic-

(C) Vincent C. Bates 2017. The content of this article is the sole responsibility of the author. The ACT Journal and the Mayday Group are not liable for any legal actions that may arise involving the article's content, including, but not limited to, copyright infringement. 
es, our critical theories can sometimes ring hollow, lacking honesty and humility. Along these lines, Stephen Eric Bonner (2017) has critiqued the insularity of modern critical theory:

A lack of historical and political perspectives has left critical theory with little to contribute in formulating a transformative enterprise for our time. But this alone was what set critical theory apart from "traditional" theory. Thus, ironically (or, better, dialectically), preserving its radical identity is precisely what calls for subjecting contemporary critical theory to immanent political critique. (kindle 693-6)

Scholarly presentations and publications by associations in which likeminded people regularly interact to share research can sometimes amount to "preaching to the choir." General agreement, even within critical theory, can precipitate unexamined assumptions and beliefs, particularly when critique is directed only at "outsiders"; internal beliefs are taken-for-granted as right and good while externalities are potentially misunderstood or stereotyped.

The intent of the MDG and ACT has always been to foster a critical stance within our networks of teachers and scholars. At our colloquia, presentations have been intended as "provocations"-to spur critical thought within the group. A similar aim is evident in the basic mission of ACT: "Founded in 2001, the journal publishes "critical, analytical, theoretical, and policy development articles of international interest that illuminate, extend, or challenge the Action Ideals of the MayDay Group" (emphasis added). It is neither expected nor necessary that all articles published in ACT support the overall agenda or tenor of the MDG; over the years, we have published some articles that have been critical of key aspects. Not only is this healthy, it is also essential in maintaining the efficacy of our critical theorizing.

The articles in this issue are published in the order in which they were submitted. Consequently, William Perrine leads this issue with an article that prompted the foregoing editorial comments. Perrine sets out to critique the concept of "liberating tolerance" articulated by Herbert Marcuse, a concept and practice that, in Perrine's words, "denies space within social discourse for particular points of view deemed dangerously regressive." Perrine argues that critical theory, given its twin aims to emancipate others from "false consciousness" and its general lack of fallibility (due, in part, to its insularity), places it within the realm of ideology as a theoretically closed system. He provides multiple illustrations of

Bates, Vincent C. 2017. Introduction to ACT 16.2. Action, Criticism, and Theory for Music Education 16 (2): 1-5. doi:10.22176/act16.2.1 
this phenomenon from within ACT and other music education publications where specific theorists seem to have been less than generous or forthright in their characterizations of conservative or traditional views and practices in music education, large ensembles in particular. Perrine argues for a form of pure tolerance whereby all sides approach others with openness and sincerity.

Eve Ruddock follows with qualitative/critical research exploring how music institutions tend to label people as either musical or not, thereby closing people off to the possibilities of full participation. She points out that "humans are both biologically and culturally musical, yet many individuals in Western cultures live with a deep conviction that they are 'musically inadequate'." Through a process of "hermeneutic exploration," Ruddock examines qualitative data from interviews with three participants "to recognize assumptions that play against inclusive musicking." She concludes that it may be better to view musicality as a cultural process in which people engage, rather than as something people possess. "To insist that music is something made by expert musicians is to fail to acknowledge the crucial part that musicking plays in our everyday lives as we respond and connect through sound, rhythm, and movement."

In the third article, Edward McClellan speaks to the issue of identity in music teacher education. This research is a good fit for ACT considering that some of our most cited articles have been those by Roberts, Bouij, Bernard, and others on this topic. Building from a comprehensive literature review, McClellan develops a theoretical framework for studying music teacher identity. His hope is that the "review of literature may reveal a theoretical framework based around tenets of commonly studied constructs in the social-cognitive theory, social identity theory, symbolic interactionism, and role theory to ground future research on music teacher constructs which may be examined through both quantitative and qualitative measures." The result, for readers of ACT and music education sociologists, is a thoughtful and thorough historical overview of the field of sociology in music education from roots in symposia organized by Hildegard Froehlich and Steve Paul, and continuing through an ongoing series of biennial symposia involving a growing number of researchers.

Next, Thomas A. Regelski once more puts forth a praxial philosophy for music education and speaks against music education as aesthetic education, which he argues continues to result "in 'classical' music being regarded as a rare leisure time pursuit while other musics were downgraded as mere entertain-

Bates, Vincent C. 2017. Introduction to ACT 16.2. Action, Criticism, and Theory for Music Education 16 (2): 1-5. doi:10.22176/act16.2.1 
ments-despite their ubiquity in society." However, this article is not simply a repeat of previously published material. Rather, Regelski infuses his praxial philosophy with many new insights and analyses. For instance, he includes a discussion of the contradiction between the values and aims of university schools of music and those necessary for primary and secondary schooling. "Therefore, the many attitudes, values, dispositions, practices, and paradigms that music teachers often accept uncritically from their professional musical training are typically unsuited to the different expectations, needs, and conditions of universal schooling!" He also compares his praxial philosophy with pragmatism, focusing on, but not limiting the discussion to Dewey. In particular, Regelski provides characteristically well-documented expositions regarding intentionality ("mindfulness or intelligent and attentive guidance of actions 'steered' toward meeting a valued need or confronting a challenging problem") and cultural naturalism: "Meaning and value are therefore naturalized and understood in terms of overt empirical consequences in praxis, not just in cerebral terms or otherwise presumed to happen as is claimed for covert aesthetic experience." Musical experiences are consummatory experiences wherein musical intentionality is situated as integral to the pragmatic realism of everyday social/culture life, thereby promoting, for students in schools, "lasting attitudes, values, and dispositions for musicing outside the school day and after graduation."

Finally, we have included an article from Pedro S. Boia and Graça BoalPalheiros who take an in-depth look at an El Sistema rehearsal in Portugal. They "discuss to what extent discipline and authority, as constituents of orchestral socialization, may be empowering by developing the participants' skills or, on the contrary, symbolically violent and boring." They further stress the importance of developing symmetrical perspectives that avoid one-sided accounts of either positive or negative sides of El Sistema-inspired programs, but rather explore complexity, contradictions, and ambivalence. They contrast what tends to be a controlling environment with practices that might be more "emancipatory and respectful." This careful look at El Sistema can be viewed as an extension of the scholarly efforts of those who participated in Volume 15, Issue 1 (January 2016), a special El Sistema issue of ACT. Even though this work is specific to El Sistema, it remains particularly relevant to music education in areas of the world in which school music centers on the large ensemble. In fact, the orchestral rehearsal under examination is an opportunity to present a critical reflection on the role and

Bates, Vincent C. 2017. Introduction to ACT 16.2. Action, Criticism, and Theory for Music Education 16 (2): 1-5. doi:10.22176/act16.2.1 
contradictions of discipline itself in youth orchestra projects and music education in general.

This issue of ACT will be followed by a special "institutional injustices" issue edited by Deb Bradley (editor-in-chief for MDG Publications) and a special issue on technology and music education edited by Brent Talbot (associate editor for ACT). Plans for 2018 include a regular issue featuring articles from MDG 29; a special collection of articles from the International Symposium on the Sociology of Music Education guest edited by Gareth Dylan Smith and Clare Hall; a commemorative issue reflecting on the 30th MDG colloquium and 25th year of the MDG; and a special issue addressing colonialism in music education, especially as it pertains to the global South, guest edited by Guillermo Rosabal-Coto, Favio D. Shifres, and Daniel H. Gonnet.

I would like to express my deepest gratitude to Anita Prest, Dan Shevock, and Emmett O'Leary who, despite busy teaching schedules and their own scholarly endeavors, continue to help with the production of ACT. With this issue, we also extend a warm welcome to Naomi Leadbeater who has graciously joined our production team. This work is completed strictly on a volunteer basis and it is well worth it, we feel, as a service to the MDG and the international field of music education, preserving and promoting free and open-access, along with double-blind peer review. Finally, I would like to thank you, members of the MDG and readers of ACT who (along with others) continue to support the work of this journal through financial donations to the MDG, but especially through your scholarly contributions.

\section{Reference}

Bonner, Stephen Eric. 2017. Critical theory and resistance: On antiphilosophy and the philosophy of praxis. In The Palgrave handbook of critical theory, edited by Michael J. Thompson. Palgrave Macmillan US. Kindle Edition.

Bates, Vincent C. 2017. Introduction to ACT 16.2. Action, Criticism, and Theory for Music Education 16 (2): 1-5. doi:10.22176/act16.2.1 